\title{
O PROCESSO dE INCLUSÃo dE ALUNOS SURdOS NAS ESCOLAS SOB O PONTO DE VISTA DO PROFESSOR DE GEOGRAFIA
}

\author{
Ricardo Lopes Fonseca* \\ Eloiza Cristiane Torres
}

Resumo: Este estudo engloba as principais características sobre a educação inclusiva do aluno surdo nas salas de aulas. A expectativa é que os pensamentos aqui mencionados sejam de fácil compreensão para o leitor e que consigam despertar a consciência e o senso crítico com referência à situação do modelo de inclusão de alunos surdos nas escolas públicas do Brasil. Essa discussão é direcionada para a variedade de implicações sobre o ensino de Geografia para os alunos surdos, visto que o ensino para alunos surdos deve ser visto com muita atenção, já que as propostas pedagógicas direcionadas para o indivíduo surdo têm como finalidade possibilitar o crescimento total de suas capacidades, porém, o que se percebe é que não é isso que ocorre nas salas de aulas.

Palavras-chave: educação, surdo, aluno, escola, Geografia.

\section{THE PROCESS OF INCVLUSION OF DEAF STUDENTS IN SCHOOLS UNDES THE STANDPOINT OF THE TEACHER OF GEOGRAPHY}

\begin{abstract}
This study deals with the main characteristics about the inclusive education for deaf students in the classroom. The thoughts mentioned are expected to be easy for the reader understanding and able to raise the awareness and critical thinking according to the inclusion model for deaf students in public schools in Brazil. This discussion is directed to the variety of implications about geography teaching for deaf students. The education for deaf students should be carefully observed since the educational proposals directed to this group have the goal to make possible the total development of their capacity. However, it is not what happens in classrooms. This essay aims to apply a variety of methodologies for geography teaching in classrooms with deaf and hearing students in order to investigate the importance of each pedagogical possibility applied, and check if it is possible to use them in classroom with both groups of students.
\end{abstract}

Keywords: education, deaf, student, school, Geography.

\section{Introdução}

O ensino para alunos surdos deve ser tratado com muita delicadeza, uma vez que as propostas pedagógicas encaminhadas para o sujeito surdo têm como objetivo promover o desenvolvimento total de suas capacidades, porém, não é isso que se nota em salas de aulas. Grande parte das práticas pedagógicas que envolvem os surdos apresenta uma série de limitações e, ao concluir o ensino básico, eles não são capazes de ler e escrever adequadamente.

\section{Abordagem histórica da educação do surdo}

Pesquisando a educação de sujeitos surdos, encontram-se indícios de que começou a ser levada em consideração somente a partir do século XVI. Antes desse período, durante a Antiguidade e Idade Média, acreditava-se que os surdos fossem estúpidos e por isso não seriam educados.

\footnotetext{
* Licenciado em Geografia pela Universidade Estadual de Maringá (UEM), mestre pelo Programa de Mestrado em Geografia: Dinâmica Espaço Ambiental da Universidade Estadual de Londrina (UEL). Atuando principalmente com os seguintes temas: métodos e práticas em ensino de Geografia e inclusão de alunos com necessidades especiais. E-mail: ricardolopesfonseca@hotmail.com.

** Doutorado em Geografia pela Universidade Estadual Paulista Júlio de Mesquita Filho. Professora adjunta da Universidade Estadual de Londrina. E-mail: elotorres@uel.br.
} 
Ainda no século XVI, era frequente manter em mistério o modo como se conduzia a educação dos surdos. Cada pedagogo trabalhava sozinho e não era comum a troca de experiências. Logo, encontram-se dificuldades em saber o que era feito naquela época, em consequência, muitos dos trabalhos desenvolvidos se perderam (LACERDA, 1998).

Nas primeiras tentativas de educar um sujeito surdo, a linguagem escrita desempenhava papel importante, pois, os alfabetos digitais eram muito utilizados. Esses alfabetos eram criados pelos próprios professores, uma vez que tinham como argumento para tal utilização o fato de que dessa forma os surdos podiam compreender o que se dizia. Naquela época a maioria dos professores começava os ensinamentos da "leitura-escrita", em seguida o professor aprimorava métodos diferentes para estimular a aptidão do alunado, por exemplo: leitura labial e/ou articulação das palavras (LACERDA, 1998).

No começo do século XVIII, a pedagogia do surdo passa por certa onda de mudanças significativas, uma vez que durante um breve período alargou-se a relação de métodos orais e métodos gestuais, que configuraram duas bússolas divergentes na educação do surdo e que perduram até os dias de hoje. Os oralistas exigiam que os surdos adquirissem o dom da fala, e que não demonstrassem que eram surdos. Já os gestualistas eram mais compreensíveis perante as dificuldades dos surdos com a linguagem falada, foram capazes de observar que os sujeitos surdos desenvolviam uma linguagem própria e eficaz para se comunicarem (LACERDA, 1998).
Os avanços e a divulgação das práticas pedagógicas com surdos foram apresentados, em 1878, em Paris, no I Congresso Internacional sobre a Instrução de Surdos. Nesse mesmo congresso, houve debates acalorados a respeito das experiências e impressões sobre o trabalho realizado até então. Alguns grupos defendiam a ideia de que falar era melhor do que usar sinais, mas que estes eram muito importantes para a criança poder se comunicar.

Dois anos depois, em 1880, foi realizado o II Congresso Internacional sobre a Instrução de Surdos, em Milão, que trouxe uma completa mudança nos rumos da educação de surdos e, justamente por isso, ele é considerado um marco histórico. Segundo Lacerda (1998):

[...] o congresso foi preparado por uma maioria oralista com o firme propósito de dar força de lei às suas proposições no que dizia respeito à surdez e à educação de surdos. Apresentaram-se muitos surdos que falavam bem, para mostrar a eficiência do método oral. Com exceção da delegação americana (cinco membros) e de um professor britânico, todos os participantes, em sua maioria europeus e ouvintes, votaram por aclamação a aprovação do uso exclusivo e absoluto da metodologia oralista e a proscrição da linguagem de sinais. Acreditava-se que $o$ uso de gestos e sinais desviasse o surdo da aprendizagem da língua oral, que era a mais importante do ponto de vista social. As resoluções do congresso (que era uma instância de prestígio e merecia ser seguida) foram determinantes no mundo todo, especialmente na Europa e na América Latina.

As decisões tomadas no Congresso de Milão levaram a que a linguagem gestual fosse praticamente banida como forma de comunicação a ser utilizada por pessoas 
surdas no trabalho educacional. Ainda para Lacerda (1998):

[...] com o Congresso de Milão termina uma época de convivência tolerada na educação dos surdos entre a linguagem falada e a gestual e, em particular, desaparece a figura do professor surdo que, até então, era frequente. Era o professor surdo que, na escola, intervinha na educação, de modo a ensinar/transmitir certo tipo de cultura e de informação através do canal visogestual e que, após o congresso, foi excluído das escolas.

Durante quase um século, desde o Congresso de Milão, o oralismo foi o referencial assumido e as práticas educacionais vinculadas a ele foram amplamente desenvolvidas e divulgadas, a abordagem não foi, praticamente, questionada. Os resultados de muitas décadas de trabalho nessa linha, no entanto, não mostraram grandes sucessos, a maior parte dos surdos profundos não desenvolveu uma fala socialmente regular e, em geral, esse desenvolvimento era parcial e tardio em relação à aquisição de fala apresentada pelos ouvintes, implicando um atraso de desenvolvimento global significativo. Somadas a isso, estavam as dificuldades ligadas à aprendizagem da leitura e da escrita: sempre tardia, cheia de problemas, mostrava sujeitos, muitas vezes, apenas parcialmente alfabetizados após anos de escolarização. Muitos estudos apontam para tais problemas, desenvolvidos em diferentes realidades e que acabam revelando sempre o mesmo cenário: sujeitos pouco preparados para o convívio social, com sérias dificuldades de comunicação, seja oral ou escrita, tornando claro o insucesso pedagógico dessa abordagem (LACERDA, 1998).
No início dos anos de 1950, com as descobertas de novas técnicas, surge uma nova investida para a educação voltada para a vocalização. Foram desenvolvidas novas técnicas para que a escola pudesse trabalhar sobre aspectos da percepção auditiva e de leitura labial da linguagem falada, surgindo assim um grande número de métodos, dando oportunidade a momentos de nova esperança de que, com o uso de próteses, se pudesse educar crianças com surdez grave e profunda a ouvir e, consequentemente, a falar.

Já na década de 1960, começaram a aparecer trabalhos sobre as línguas de sinais utilizadas pelas sociedades surdas. Mesmo com a proibição dos oralistas no uso de gestos e sinais, raramente se encontrava uma escola ou instituição para surdos que não tivesse desenvolvido, às margens do sistema, um modo próprio de comunicação através de sinais.

O desgosto com o oralismo e os trabalhos sobre línguas de sinais resultaram na origem de novas propostas pedagógico-educacionais em relação à educação da pessoa surda, e a tendência que ganhou impulso nos anos 1970 foi a chamada comunicação total. "A Comunicação Total é a prática de usar sinais, leitura orofacial, amplificação e alfabeto digital para fornecer inputs linguísticos para estudantes surdos, ao passo que eles podem expressar-se nas modalidades preferidas" (STEWART, 1993). O principal objetivo era fornecer à criança a possibilidade de desenvolver uma comunicação real com seus familiares, professores e semelhantes. A esse respeito, diz Lacerda (1998) que "a comunicação total pode utilizar tanto sinais retirados da língua de sinais usada pela comunidade surda quanto sinais gramaticais modificados $\mathrm{e}$ 
marcadores para elementos presentes na língua falada, mas não na língua de sinais". Moura (1993) complementa a ideia: "tudo o que é falado pode ser acompanhado por elementos visuais que o representam, o que facilitaria a aquisição da língua oral e posteriormente da leitura e da escrita".

Alguns trabalhos abordam as práticas reunidas sob o nome de Comunicação Total, em suas várias acepções, que foram amplamente desenvolvidas nos Estados Unidos e em outros países nas décadas de 1970 e 1980 e muitos estudos foram realizados para verificar sua eficácia. O que esses estudos têm apontado é que, em relação ao oralismo, alguns aspectos do trabalho educativo foram melhorados e que os surdos, no final do processo escolar, conseguem compreender e se comunicar um pouco melhor. Entretanto, segundo essas análises avaliativas, eles apresentam ainda sérias dificuldades em expressar sentimentos e ideias e comunicar-se em contextos extraescolares. Em relação à escrita, os problemas apresentados continuam a ser muito importantes, sendo que poucos sujeitos alcançam autonomia nesse modo de produção de linguagem. Observam-se alguns poucos casos bem-sucedidos, mas a grande maioria não consegue atingir níveis acadêmicos satisfatórios para sua faixa etária. Em relação aos sinais, estes ocupam um lugar meramente acessório de auxiliar da fala, não havendo um espaço para seu desenvolvimento. Assim, muitas vezes, os surdos atendidos segundo essa orientação comunicam-se precariamente apesar do acesso aos sinais.

O que a Comunicação Total favoreceu de maneira efetiva foi o contato com sinais, que era proibido pelo oralismo, esse contato proporcionou que os surdos se dispusessem à aprendizagem das línguas de sinais, externamente ao trabalho escolar. Essas línguas são comumente utilizadas entre os alunos, enquanto na relação com o professor é usado um misto de língua oral com sinais. Voltando a Lacerda (1998):

[...] o objetivo da educação bilíngue é que a criança surda possa ter um desenvolvimento cognitivo-linguístico equivalente ao verificado na criança ouvinte, e que possa desenvolver uma relação harmoniosa também com ouvintes, tendo acesso às duas línguas: a língua de sinais e a língua majoritária.

Para Moura (1993), "O fato é que tais línguas foram sistematicamente rejeitadas e só recentemente têm sido valorizadas pelos meios acadêmicos e pelos próprios surdos". O sistema bilíngue possibilita também que, dada a relação entre o adulto surdo e a criança, esta possa construir uma autoimagem positiva como sujeito surdo, sem perder a possibilidade de se integrar numa comunidade de ouvintes. A língua de sinais poderia ser introduzida pela criança surda como uma língua valorizada, coisa que até hoje tem sido bastante difícil apesar de esta ocupar um lugar central na configuração das comunidades surdas.

Em cada país, o aprofundamento dos estudos sobre sua língua de sinais é diferente, e só em alguns casos, estão bastante desenvolvidos. Por exemplo, nos Estados Unidos, a Língua Americana de Sinais é bastante conhecida, sendo talvez a mais bem estudada até hoje. Entretanto, lá, as práticas de comunicação total são prevalentes, indicando que o desenvolvimento do conhecimento acadêmico sobre as línguas de sinais não é suficiente para sua efetiva inserção no atendimento 
educacional. Em outros países, tais estudos ainda estão no começo, ajudando pouco aqueles que desenvolvem práticas de educação bilíngue. Tais práticas remetem a um universo amplo de questões ainda pouco explorado, que parece apresentar vários problemas ao mesmo tempo em que aponta para formas de atendimento mais adequadas às pessoas surdas (MOURA, 1993).

É possível constatar que, de alguma maneira, as três principais abordagens de educação de surdos - oralista, comunicação total e bilinguismo - coexistem, com adeptos de todas elas em diferentes países. Cada qual com seus prós e contras, dessa forma fica aberto espaço para reflexões na busca de um caminho educacional que de fato favoreça o desenvolvimento pleno dos sujeitos surdos, contribuindo para que sejam cidadãos em nossa sociedade.

\section{Aspectos da surdez}

Segundo o Decreto n. 5.626, de 22 de dezembro de 2005, pessoa surda é aquela que, "[...] por ter perda auditiva, compreende e interage com o mundo por meio de experiências visuais, manifestando sua cultura principalmente pelo uso da Língua Brasileira de Sinais - Libras".

Como vimos, muito há para ser levado em consideração sobre a existência de comunidades de surdos, pois são tantas ideias que divergem entre si que verifica-se a necessidade de algumas premissas serem levadas em consideração.

Primeiramente, o surdo é uma pessoa normal ou não? Prestando-se devida atenção ao que já foi dito, o mais contraditório de tudo está relacionado ao fato "normalidade" ou "anormalidade" do surdo, há muita contradição no que a sociedade considera normal ou anormal, pois assim como vários outros grupos que sofrem preconceitos $e$ restrições da sociedade, tal como os pobres e negros, por exemplo, o surdo também sofre, logo, ele teria que ser considerado membro da sociedade, uma vez que, como diz Bueno (1998), "[...] ele não deve ser considerado como excepcional, nem como patológico. Mas não se pode considerá-lo como normal, já que ele sofre uma restrição".

Essa restrição imposta pela sociedade pode ser percebida também em outros grupos sociais que têm características diferentes, ou seja, povos de outros países também sofrem restrições sociais pelo fato de serem diferentes do que a sociedade local determina. Logo o surdo não pode ser considerado normal, pois ele possui suas características que o difere da maioria da sociedade.

Um segundo ponto: a surdez deve ser considerada como deficiência? Pois bem, para alguns autores como Moura (1996), "[...] considero que não existe possibilidade de considerar o surdo como normal. Ele não o é [...]. Os surdos pertencem a um grupo minoritário que sofre uma restrição que precisa ser compreendida na sua plenitude".

Como se pode observar, todas as evidências sociais e culturais afirmam que $o$ surdo é deficiente, além do mais, seria um erro não considerar-se o quadro patológico do surdo, pois não se deve achar que o surdo faça parte de um grupo de minorias sociais e confundi-los com outros grupos, pois uma coisa é a patologia e outra a diferença social. Entretanto, se não fosse patológico o 
problema do surdo, qual seria a explicação para aqueles que nasceram surdos oriundos de algum problema que a mãe teve durante a gravidez, como por exemplo, a rubéola?

Seria patológico caso a sociedade quisesse eliminar as características que marcam diversas outras sociedades que diferem da sua? A resposta a essa pergunta é negativa, pois não se trata de um problema que pode ser corrigido, isto é, não se trata de algo que possa prevenir e/ou solucionar alguma enfermidade, mas trata-se de diferenças culturais, que marcam uma determinada sociedade e que difere de outras tantas.

O problema com relação à surdez, assim como com deficiências em geral, é que, como ela não afeta diretamente as possibilidades de sobrevivência e, em grande parte dos casos, até o momento atual, não é passível de reversão, há que se encontrar formas democráticas de conviver com os surdos. Portanto, entende-se que a surdez seja uma deficiência do ponto de vista patológico e diferença social do ponto de vista cultural. Para Bueno (1998):

[...] O nó da questão da integração social do indivíduo surdo, envolvendo a existência de grupos de surdos e sua convivência com os ouvintes, pode ser assim colocado: apesar de ser uma condição intrinsecamente adversa, a surdez e os surdos não podem ser tratados meramente como doentes, pois não o são. Essa visão só poderá ser modificada se ultrapassarmos as decorrências diretas da perda auditiva e analisarmos de forma mais abrangente as consequências geradas por ela, aliadas às consequências construídas e produzidas pelas relações sociais.

Para tal, defender a existência de comunidades surdas, considerando a língua de sinais como sua primeira língua, em contraposição a uma língua imposta pela "sociedade ouvinte", é contribuir para a superação de sua condição socialmente adversa.

Por outro lado, desconsiderar o fato de que existem agrupamentos de surdos que se utilizam de formas de representação diferentes daquelas utilizadas por ouvintes, e ainda, exigir deles a mesma produtividade em relação à linguagem oral dos que ouvem não é a resposta para todas as perguntas a que se tem de responder.

\section{Os professores de Geografia}

Os métodos que os professores utilizam em sala de aula serão discutidos nesta parte do trabalho. Para tal tarefa, foram entrevistados alguns professores de geografia de escolas públicas e da escola especializada.

Diferente da visão de diretores, coordenadores e pedagogos de escola é a dos professores, os mediadores desse conflito, ensinar alunos surdos e ouvintes com a mesma metodologia. São os professores que sentem na pele como o sistema de inclusão de alunos surdos nas escolas públicas está sendo realizada de forma "populista" pelos representantes do governo, visando agradar a população que, na sua maioria, está desinformada desse tipo de prática.

Mas não é só a questão das práticas pedagógicas que serão considerados, mas também, a relação entre professor e aluno surdo e professor e intérprete. 


\section{Professores de geografia de escolas públicas}

O professor, em particular o de geografia, encontra muitas dificuldades para ensinar determinado conteúdo geográfico para uma turma com estudantes ouvintes e surdos. Nota-se que, na maioria das vezes, há um esforço da parte desse professor para educá-los todos, inclusive os surdos. Nota-se ainda que o professor tem a garra para, a todo custo, fazer com que o aluno surdo aprenda como os ouvintes, mesmo quando na sala de aula há um intérprete.

Conversando com alguns professores de escolas públicas de Maringá, constatou-se alguns outros pontos relevantes para este trabalho que serão expostos a seguir. Os professores participantes da entrevista serão identificados pelas letras do alfabeto, com a finalidade de evitar sua identificação pessoal.

Professor A de Geografia: "trabalhar com alunos ouvintes e surdos numa mesma sala de aula não é fácil, o planejamento das aulas requer toda uma mudança, há turmas da mesma série que não posso trabalhar da mesma forma".

Professor B de Geografia: "essa ideia [de inclusão] está toda errada. Não culpo o aluno por ele ser surdo, mesmo porque sei, por exemplo, que sua percepção para observações, na maioria dos casos, é muito melhor que a de muitos alunos ouvintes, a culpa é do sistema de governo que não conhece ou finge que não conhece a falta de recursos das escolas para o processo de inclusão".

Não é novidade que os professores também estejam desgostosos com essa forma de incluir em escolas públicas os estudantes que necessitam de um ensino diferenciado.

Professor C de Geografia: "que há falhas nesse sistema, é claro que há, no meu ponto de vista a maior delas está nos intérpretes, são eles que traduzem nossas informações para os alunos, mas nem sempre eles conseguem isso, pois mesmo sendo tradutores não têm formação em todas as áreas de ensino".

Professor D de Geografia: "toda vez que entro em uma sala de aula que possui um intérprete, sinto-me como se estivesse sendo avaliado, fico tenso, com medo de cometer alguma gafe, penso muitas vezes que posso falar algo e o intérprete me corrigir na frente de toda a sala, sinceramente, fico constrangido na presença deles, não pela pessoa deles, pois são pessoas maravilhosas, mas sim pelo profissional de traduções".

Professor E de Geografia: "mesmo fazendo-se necessário, não gosto da ideia de ter que fazer reuniões pedagógicas com os tradutores para que em determinados conteúdos eu tenha que mudar algumas coisas para poder ficar, digamos assim, mais fácil para os intérpretes poderem traduzir para os alunos surdos".

Ora, nota-se que os professores sentem-se inseguros na presença do tradutor, ficam encabulados e nervosos, muitas vezes com a tensão que eles criam (muitas vezes sem necessidades, pois os tradutores são extremamente profissionais) acabam se perdendo nas aulas.

Compreende-se a opinião desses professores, já é bastante difícil quando no estágio o professor estagiário é avaliado pelo professor titular da turma e, em alguns 
casos, pelo professor responsável pela disciplina de supervisão de estágio da faculdade, é bastante desconfortável a presença de outro adulto na mesma sala de aula gesticulando tudo o que se fala.

Quanto às reuniões pedagógicas, como diz o Professor $\mathrm{E}$, deve ser realmente desagradável o professor ter que mudar sua forma de conduzir a aula para que o intérprete possa fazer melhor sua tradução, mas haveria esse tipo de problema se o intérprete tivesse formação em geografia e mesmo em todas as outras disciplinas a que ele presta traduções? Será que deve o professor submeter-se a essas reuniões e modificar suas aulas para atender as necessidades do tradutor? Enfim, acredito que a resposta para as duas perguntas deveria ser não.

Procurando entender a primeira questão: é certo que se o intérprete possui formação de geografia, conseguirá facilmente fazer as traduções necessárias, uma vez que por ter feito a graduação de geografia ele conhece os termos geográficos e tantos outros assuntos da geografia e faria as suas traduções sem muita dificuldade. Em relação a segunda questão, o professor não deve mudar sua forma de ensinar por causa do intérprete e sim o intérprete se adequar à forma como o professor aplica sua aula, mesmo porque o professor, geralmente, modifica sua aula pelo aluno surdo que precisa de outros tipos de metodologias. Mesmo porque a inclusão em questão, é do aluno e não do intérprete.

Professor F de Geografia: "confesso que minhas práticas pedagógicas são um tanto quanto monótonas nas salas que tenho algum aluno surdo, como não posso utilizar o som como metodologia de ensino, como a música, por exemplo, faço minhas aulas da maneira mais tradicional, isto é, me concentro em ficar escrevendo no quadro negro e expondo o conteúdo de forma oral seguido da tradução do intérprete".

Professor G de Geografia: "não é fácil criar formas de ensinar os dois grupos; as metodologias para o ensino de geografia têm que ser escolhidas bem atentamente, levando em consideração os mínimos detalhes, pois não posso correr o risco de fazer com que o aluno surdo se sinta ofendido por algo que possa ocorrer na minha aula".

A preocupação dos professores para ajustar alguma metodologia que possa ser aplicada aos dois grupos e que surta efeitos iguais é enorme; são comuns os casos em que, numa sala mista, o professor recorre a aulas tradicionais, como foi mencionado pelo Professor F, para lecionar, pois é uma forma segura de não cometer alguma gafe.

Contudo, pode-se afirmar que há a necessidade de se pensar em práticas pedagógicas dinâmicas possíveis de serem usadas em sala de aula com os alunos surdos e ouvintes e que os resultados sejam os mesmos.

\section{Considerações finais}

O surdo deve ser respeitado em sua qualidade linguística e assim, na medida em que tal condição é respeitada, poderá desenvolver e estabelecer novos conhecimentos de modo adequado e satisfatório. Assim, é necessário que as pessoas envolvidas no trabalho com alunos surdos estejam atentos a esse fato. 
Nota-se que os governantes são presunçosos a tal ponto de vincular propagandas políticas sobre a inclusão de surdos nas escolas, dando a ideia da perfeição desse sistema, de forma a tentar angariar votos dos eleitores menos instruídos que acreditam nesse sistema utópico.

É possível mudar a situação dos alunos surdos, nas salas de aulas, adotando algumas posturas, tais como:

(a) Qualificação dos professores em educação especial, uma vez que é função, quase que exclusiva do educador, formar o aluno para a vivência em sociedade, devendo esse docente estar preparado para enfrentar a diversidade de alunos que possam surgir em suas salas de aulas;

(b) Qualificação da equipe pedagógica, bem como dos funcionários que cuidam da manutenção da escola, como: porteiros, serventes e zeladores, para que todos consigam interagir com os alunos surdos; desta forma a escola estará estimulando a prática social, promovendo a interatividade social do estudante surdo;

(c) A escola deverá incentivar os alunos ouvintes a se comunicarem adequadamente com os alunos surdos, assim, a escola estará mais uma vez, instigando a promoção social, por exemplo, o ensino de Libras para as séries iniciais, eventos culturais, atividades esportivas, são algumas propostas que a escola poderá adotar;

(d) Os intérpretes deverão possuir conhecimento prévio sobre o conteúdo que o professor da disciplina for aplicar, isto é, antes de cada conteúdo ser ministrado o professor deverá fornecer ao intérprete as informações necessárias sobre o que será lecionado, para que em sala de aula o tradutor forneça ao aluno surdo o conteúdo de uma melhor forma;

(e) A comunicação com a família e a comunidade também deve ser incentivada pela escola, é através dessa comunicação, principalmente com a comunidade, que o aluno terá um melhor convívio social.

Encerramos este artigo expondo a importância da inclusão, mas desde que seja realizada de forma correta, e não só "incluir por incluir". A função de preparar o aluno para o convívio social deve ser realizada de forma coerente, ou seja, através da inclusão de alunos surdos nas escolas; devendo promover, além da aprendizagem a interatividade social de maneira semelhante e sem exclusão dos demais educandos.

\section{Referências bibliográficas}

BUENO, G. S. Surdez, linguagem e cultura.

Cadernos Cedes, Campinas:

Unicamp, n. 46, p. 41-56, 1998.

LACERDA, C. B. F. Um pouco da história das diferentes abordagens na educação dos surdos. Cadernos Cedes, Campinas: Unicamp, n. 46 , p. $68-80$, 1998.
MOURA, M. C. O surdo: caminhos para uma nova identidade. Rio de Janeiro: Revinter, 1996.

- A língua de sinais na educação da criança surda. São Paulo: Tec Art, 1993.

STEWART, D. A. Pesquisa sobre o uso de língua de sinais na educação de crianças surdas. São Paulo: Tec Art, 1993. 